\title{
Chemotherapy-induced nausea and vomiting - standards in 2012
}

\section{S. Lorenzen}

Department of Medical Oncology, National Center for Tumor Diseases, Heidelberg, Germany

Received 10 October 2011; accepted 17 January 2012

In recent years, new drugs have increased efficacy in the prevention and control of chemotherapy-induced nausea and vomiting (CINV), however, vomiting, and especially nausea continue to be two of the most worrisome adverse effects of antineoplastic treatment. Antiemetic agents that have been identified to significantly improve the prophylaxis and treatment of CINV include the $5-\mathrm{HT}_{3}$-receptor antagonists (RA), corticosteroids, neurokinin $1\left(\mathrm{NK}_{1}\right)$ receptor antagonists, dopamine receptor antagonists, benzodiazepines, neuroleptics and cannabinoids. However, there are still a significant number of patients experiencing CINV, either because of nonadherence to current treatment guidelines or due to the fact that antiemetic prophylaxis for new drugs, targeted therapies and prolonged oral therapy is not yet established appropriately. Due to the emergence of new findings and new antiemetic agents, the MASCC/ESMO and the ASCO updated their treatment guidelines for the prevention of CINV. The combination of anthracyclines and cyclophosphamide (AC) is classified as highly emetogenic and a triple therapy including a $5-\mathrm{HT}_{3}-\mathrm{RA}$, dexamethasone and an $\mathrm{NK}_{1}-\mathrm{RA}$ is recommended. While acute CINV can be sufficiently controlled with the combination of $5-\mathrm{HT}_{3}$-RA plus dexamethasone, delayed CINV still remains a significant clinical problem. Palonosetron, a second-generation $5-\mathrm{HT}_{3}-\mathrm{RA}$, provides superior protection against both, nausea and vomiting, and demonstrated superior long-lasting CINV prevention in the delayed phase. Another recently approved agent is the $\mathrm{NK}_{1^{-}}$ RA fosaprepitant, which has shown equivalency in the prevention of both, acute and delayed CINV to aprepitant, and is used as a single day intravenous prophylaxis. This review provides an update of the revised clinical guidelines for antiemetic treatment and prophylaxis in cancer patients receiving chemotherapy.

Keywords: Antiemetics, Chemotherapy-Induced Nausea and Vomiting (CINV), antiemetic guidelines, palonosetron.

\section{Introduction}

In the last two decades, substantial progress has been made in the prevention and treatment of CINV. However, CINV remains still one of the most distressing side effects of chemotherapy, impairing patient's quality of life, leading to non-compliance with treatment, dose reductions, and, as a consequence, may compromise chances of treatment success.

The Multinational Association of Supportive Care in Cancer (MASCC) suggests the classification of the chemotherapeutic agents according to their emetic potential into four emetic risk groups (minimal, low, moderate, and high). As new antineoplastic agents have been developed, these agents have been added to the emetogenic classification scheme (Table 1). With the increasing use of oral agents used in extended regimens of continuous daily use, emetogenicity of these agents has to be newly defined and therefore oral agents are ranked separately from intravenous agents (Table 2), recognizing their different schedules of administration. As oral agents rarely induce delayed emesis, antiemetic prophylaxis is only recommended on day 1 .

However, current guidelines are only considering the emetogenic potential of the chemotherapeutic agent itself and not the patient-related risk-factors which might lead to an underestimation of the emetogenic risk and, as a consequence, to an inadequate antiemetic prophylaxis. Furthermore, this classification does not take into account the emetogenic potential of combinations of targeted drugs and does not include nausea, which is not controlled as well as emesis.

\section{Antiemetic agents}

Of the various antiemetics currently available, 5-hydroxytryptamine-3(5- $\left.\mathrm{HT}_{3}\right)$ receptor antagonists, neurokinin-1 ( $\left.\mathrm{NK}_{1}\right)$ receptor antagonists and corticosteroids are the most effective agents [1].

\section{Serotonin (5- $\left.-\mathrm{T}_{3}\right)$ receptor antagonists}

All first-generation $5-\mathrm{HT}_{3}$ receptor antagonists (ondansetron, granisetron, tropisetron, dolasetron) are equally effective in 


\begin{tabular}{|c|c|}
\hline High (>90\%) & $\begin{array}{l}\text { - Carmustine } \\
\text { - Cisplatin } \\
\text { - Cyclophosphamide } \geq 1.500 \mathrm{mg} / \mathrm{m}^{2} \\
\text { - Dacarbazine } \\
\text { - Mechlorethamine } \\
\text { - Streptozotocin }\end{array}$ \\
\hline Moderate (30\%-90\%) & $\begin{array}{l}\text { - Carboplatin } \\
\text { - Cyclophosphamide }<1.500 \mathrm{mg} / \mathrm{m}^{2} \\
\text { - Cytarabine }>1.000 \mathrm{mg} / \mathrm{m}^{2} \\
\text { - Daunorubicin } \\
\text { - Doxorubicin } \\
\text { - Epirubicin } \\
\text { - Idarubicin } \\
\text { - Ifosfamide } \\
\text { - Irinotecan } \\
\text { - Oxaliplatin } \\
\text { - Azacitidine } \\
\text { - Bendamustine } \\
\text { - Alemtuzumab } \\
\text { - Clofarabine }\end{array}$ \\
\hline Low (10\%-30\%) & $\begin{array}{l}\text { - Cytarabine } \leq 100 \mathrm{mg} / \mathrm{m}^{2} \\
\text { - Docetaxel } \\
\text { - Etoposide } \\
\text { - } \text {-Fluorouracil } \\
\text { - Gemcitabine } \\
\text { - Doxorubicin HCL liposome Injection } \\
\text { - Methotrexate } \\
\text { - Mitomycin } \\
\text { - Mitoxantrone } \\
\text { - Ixabepilone } \\
\text { - Paclitaxel } \\
\text { - Pemetrexed } \\
\text { - Topotecan } \\
\text { - Trastuzumab } \\
\text { - Bortezomib } \\
\text { - Catumaxumab } \\
\text { - Panitumumab } \\
\text { - Cetuximab } \\
\text { - Temsirolimus }\end{array}$ \\
\hline Minimal (<10\%) & $\begin{array}{l}\text { - Bleomycin } \\
\text { - Busulfan } \\
\text { - 2-Chlorodeoxyadenosine } \\
\text { - Fludarabine } \\
\text { - Vinblastine } \\
\text { - Vincristine } \\
\text { - Vinorelbine } \\
\text { - Bevacizumab }\end{array}$ \\
\hline
\end{tabular}

the prophylaxis of acute high and moderately emetogenic chemotherapy when given at equivalent doses [2, 3]. However, the first-generation $5-\mathrm{HT}_{3}$ receptor antagonists are not effective in the control of delayed CINV, and there is no clinical evidence to justify their use beyond $24 \mathrm{~h}$ after chemotherapy for the prevention of delayed emesis [4]. The only $5-\mathrm{HT}_{3}$ receptor antagonist which has shown clinical efficacy in controlling delayed CINV is the second-generation $5-\mathrm{HT}_{3}-\mathrm{RA}$ palonosetron.

Palonosetron is characterized by its higher binding affinity to the $5-\mathrm{HT}_{3}$ receptor, its significantly longer half-life of approximately $40 \mathrm{~h}$ and its ability to trigger $5-\mathrm{HT}_{3}$ receptor internalization [5]. Clinical trials on chemotherapy of high and moderately emetogenic potential have shown that palonostron is at least equivalent to the first-generation $5-\mathrm{HT}_{3}-\mathrm{RA}$ in
Tab. 2: Emetogenic classification of oral chemotherapeutic agents (Adapted from [18])

\begin{tabular}{ll}
\hline High $(>90 \%)$ & - Hexamethylmelamine \\
& - Procarbazine \\
\hline Moderate $(30 \%-90 \%)$ & - Cyclophosphamide \\
& - Imatinib \\
& - Temozolomide \\
& - Vinorelbine \\
\hline Low $(10 \%-30 \%)$ & - Capecitabine \\
& - Tegafur Uracil (UFT) \\
& - Fludarabine \\
& - Etoposide \\
& - Sunitinib \\
& - Everolimus \\
& - Lapatinib \\
& - Thalidomidomide \\
& - Chlorambucil \\
& - Hydroxyurea \\
& - Gefitinib \\
& - Erlotinib \\
- Sorafinib \\
Minimal $(<10 \%)$
\end{tabular}

the control of acute CINV in moderately [6] - and in highly emetogenic chemotherapy (HEC) $[7,8]$, and superior in the control of delayed CINV [9, 10]. The study by Aapro et al. [7] demonstrated significantly higher complete response rates during the delayed (24-120h) and overall phases (0-120h) when Palonosetron was given with concomitant dexamethasone compared to ondansetron plus dexamethasone in HEC. However, only two-third of patients received pretreatment with dexamethasone. Furthermore, a study by Saito et al. [9] could demonstrate superiority of palonosetron when administered with dexamethasone in the control of CINV in the delayed phase compared to granisetron plus dexamethasone. Regarding the dosage, a recent meta-analysis could prove equivalent in terms of efficacy between the 0.25 - and the $0.75 \mathrm{mg}$ doses [11]. Based on these studies, Palonosetron was approved for the prevention of acute CINV in HEC and MEC and, as the only $5-\mathrm{HT}_{3}$-RA for the prevention of delayed nausea and vomiting in MEC. However, no study results of palonostron in combination with an $\mathrm{NK}_{1}-\mathrm{RA}$ are available so far.

\section{Neurokinin-1 $\left(\mathrm{NK}_{1}\right)$ receptor antagonists}

Aprepitant, a selective antagonist of the neurokinin 1 neurotransmitter receptor, demonstrated superior efficacy with an additional improvement in the prevention of acute emesis of $10-15 \%$ and $20-30 \%$ in delayed CINV, when combined with a $5-\mathrm{HT}_{3}-\mathrm{RA}$ and dexamethasone [12]. Additional $\mathrm{NK}_{1}-\mathrm{RA}$ such as casopitant, netupitant and rolapitant have either shown clinical promise or are still under investigation [13]. Fosaprepitant, a single day intravenous antiemetic agent, which is converted within 30 minutes into aprepitant, has demonstrated equivalence with aprepitant for nausea and emesis control in HEC and was recently approved to replace oral aprepitant [14-16]. Of note, a dose of $115 \mathrm{mg}$ fosaprepitant is bioequivalent in its area under the curve to aprepitant $125 \mathrm{mg}$. 


\section{Corticosteroids}

The addition of corticosteroids to a $5-\mathrm{HT}_{3}$ - $\mathrm{RA}$ containing antiemetic regimen or an $\mathrm{NK}_{1}$-RA has markedly enhanced the control rates of both, acute and delayed CINV. Dexamethasone is the preferred steroid in the prophylaxis of acute and delayed CINV of either moderate or high emetogenic potential. For control of acute cisplatin-induced CINV, a single dexamethasone dose of $20 \mathrm{mg}$ is recommended before chemotherapy. When used concomitantly with an $\mathrm{NK}_{1}-\mathrm{RA}$, dexamethasone dose should be adjusted to $12 \mathrm{mg}$ in HEC and $8 \mathrm{mg}$ in MEC $[3,17,18]$ as aprepitant causes a 2 -fold increase in the area under the plasma concentration curve (AUC).

\section{Updated guidelines in the prevention and therapy of CINV}

Due to the emergence of new findings and the implementation of new cytotoxic agents, targeted therapies and the increasing use of oral agents, the Multinational Association of Supportive Care in Cancer (MASCC), the European Society of Medical Oncology (ESMO) and the American Society of Clinical Oncology (ASCO) updated the emetogenic classification and the clinical antiemetic guidelines $[3,18]$. The marginal changes and the management of chemotherapy-induced emesis in different situations (Fig. 1) will be discussed here.

\section{Prevention of acute and delayed CINV in highly emetogenic chemotherapy (HEC)}

With the introduction of Aprepitant to a 5- $\mathrm{HT}_{3}$-RA and dexamethasone regimen, acute and delayed emesis following chemotherapy of high emetogenic risk, could be significantly improved [19-21] most likely due to the improvement of CINV in the first $24 \mathrm{~h}$. This effect could be maintained over multiple cycles of chemotherapy [22, 23], however, the control of nausea was only improved in the delayed period in only one study
[20]. Based on the results of these studies, a triple therapy consisting of single doses of a $5-\mathrm{HT}_{3}-\mathrm{RA}$, dexamethasone and aprepitant/fosaprepitant given before chemotherapy is recommended. This triple therapy is also a recommended treatment in patients receiving an anthracycline plus cyclophosphamide (AC) combination [21], which was recently reclassified as a highly emetogenic chemotherapy regimen based on the high emetic potential of these two agents.

\section{Antiemetic treatment in HEC}

For acute emesis on day 1 :

5- $\mathrm{HT}_{3}$ receptor antagonist:

Preferably Palonosetron $0.50 \mathrm{mg}$ p.o.; $0.25 \mathrm{mg}$ i.v.

Granisetron $\quad 2 \mathrm{mg} /$ p.o.; $1 \mathrm{mg}$ or $0.01 \mathrm{mg} / \mathrm{kg}$ i.v.

Ondansetron $\quad 8 \mathrm{mg}$ p.o. twice daily; $8 \mathrm{mg}$

$\mathrm{NK}_{1}$ Antagonist:

Aprepitant $125 \mathrm{mg}$ p.o./Fosaprepitant $115 \mathrm{mg}$ i.v.

Corticosteroid:

Dexamethasone $12 \mathrm{mg}$ i.v./p.o.

For delayed emesis on days 2 and 3 :

Aprepitant $80 \mathrm{mg} /$ day p.o.

Dexamethasone $4 \mathrm{mg}$ every $12 \mathrm{~h}$ p.o. or i.v.

\section{Prevention of acute and delayed CINV in moderately emetogenic chemotherapy (MEC)}

In non-AC MEC regimens, the updated ASCO and MASCC/ ESMO guidelines recommend the double therapy of a $5-\mathrm{HT}_{3}$ RA and a corticosteroid as standard prophylaxis. The addition of aprepitant might be also beneficial in the prevention of CINV in patients with MEC [24] with the additional advantage of abbreviating dexamethasone dosing, however, additional

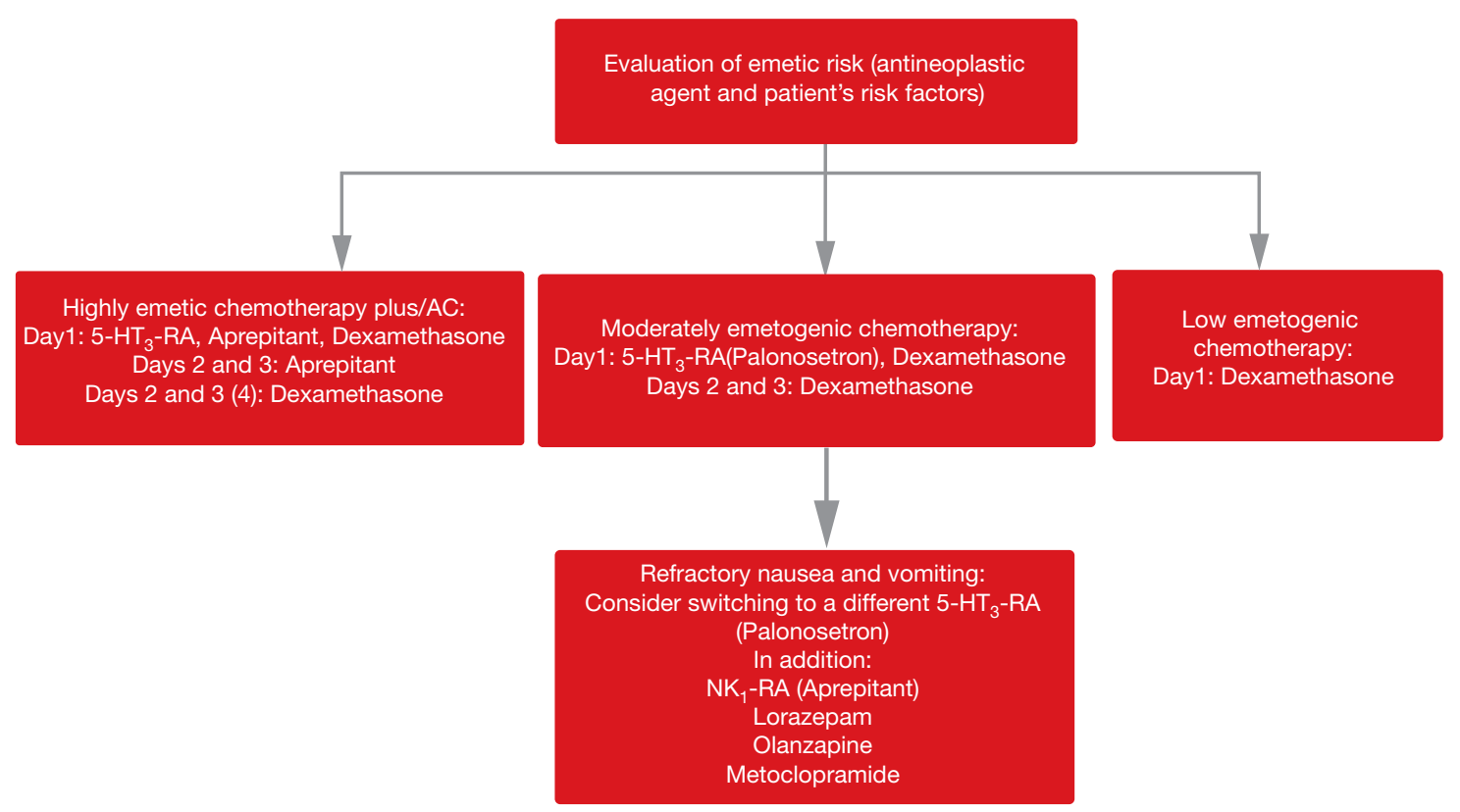

Fig. 1: Treatment algorithm for prophylaxis of CINV 
studies are warranted to further determine the appropriate use of aprepitant in this setting.

\section{Antiemetic treatment in MEC}

For acute emesis on day 1 :

5- $\mathrm{HT}_{3}$-RA:

Preferably Palonosetron $0.50 \mathrm{mg}$ p.o.; $0.25 \mathrm{mg}$ i.v.

\section{Corticosteroid:}

Dexamethasone $\quad 8 \mathrm{mg}$ i.v./p.o.

For delayed emesis on days 2 and 3 :

Dexamethasone $\quad 4 \mathrm{mg}$ every $12 \mathrm{~h} \mathrm{p.o.}$

\section{Prevention of acute and delayed CINV in low} and minimal emetogenic chemotherapy

In patients with no prior history of CINV submitted to low emetogenic chemotherapy, a single agent such as dexamethasone ( $8 \mathrm{mg}$ oral or iv), a $5-\mathrm{HT}_{3}$-RA or a dopamine RA should be used as prophylaxis on day one, whereas for days 2 and 3 no prophylaxis is recommended. In chemotherapy with minimal emetogenic potential no antiemetic treatment should be administered routinely.

\section{Multiday chemotherapy}

For patients receiving multiday chemotherapy, antiemetics should be administered according to the emetogenic risk class of the antineoplastic agent, and should be given on each day of chemotherapy and for additional 2 days after. Palonostron is the only $5-\mathrm{HT}_{3}-\mathrm{RA}$ approved for delayed CINV, therefore the combination of palonosetron and dexamethasone daily during each day of chemotherapy might be a promising treatment approach in this setting [25]. However, a specific dosing schedule still needs to be defined. Instead of taking a serotonin antagonist daily, patients can also be offered the granisetron transdermal patch that delivers therapy over multiple days in high-or moderate-risk chemotherapy [26].

The severity of CINV in patients receiving multiday cisplatin-based chemotherapy can be improved by using a combination of a $5-\mathrm{HT}_{3}$-RA plus dexamethasone for acute, and dexamethasone alone for delayed nausea and vomiting. The addition of an $\mathrm{NK}_{1}$-RA to the standard combination of a firstgeneration $5-\mathrm{HT}_{3}-\mathrm{RA}$ and dexamethasone might have an additional benefit [27] and the recently updated ASCO guidelines recommend the additional use of aprepitant for patients receiving 5-day cisplatin therapy [3].

In addition, olanzapine, a thienobenzodiazepine with a high affinity to several receptors involved in the CINV pathway such as dopamine, serotonine and histamine receptors, has demonstrated activity in the prevention of acute and delayed CINV in patients receiving MEC or HEC [28-30]. The combination of olanzapine with standard $5-\mathrm{HT}_{3}-\mathrm{RA}$ and dexamethasone might be another reasonable treatment strategy to control CINV in multiday chemotherapy regimens.

\section{Antiemetic salvage therapy}

In patients who fail antiemetic prophylaxis and/or rescue therapy despite optimal prophylaxis, clinicians should reevaluate emetic risk, disease status, concurrent illness and medication. According to the current ASCO and NCCN guidelines, switching to a different $5-\mathrm{HT}_{3}-\mathrm{RA}$ or adding other agents such as lorazepam or alprazolam, dopamine antagonists such as high-dose intravenous metoclopramide or olanzapine or cannabinoids, are reasonable treatment options for patients refractory or intolerant to $5-\mathrm{HT}_{3}-\mathrm{RA}$, dexamethasone and $\mathrm{NK}_{1}-\mathrm{RA}$ [17]. Of note, aprepitant is only approved for the prevention of CINV and should not be used in the treatment of existing nausea and vomiting.

\section{Anticipatory nausea/vomiting}

Anticipatory nausea and vomiting occur prior to the administration of chemotherapy and is triggered by the adverse memory of prior CINV. Its incidence ranges from $10-45 \%$, with predominance of nausea. Prevention of CINV with the most active antiemetic regimens is therefore of utmost importance. However, if anticipatory nausea and emesis occur, behavioural therapy with systematic desensitization is suggested [3].

\section{Conclusion}

Despite a wide armamentarium of antiemetic drugs, there is still much to be achieved in the prediction and treatment of CINV. Besides the remarkable improvement in the control of vomiting, nausea remains a significant problem in patients receiving moderately and highly emetogenic chemotherapy, also because the emetic risk classification does not include nausea. $\mathrm{NK}_{1}$-RA and 5- $\mathrm{HT}_{3}$-RA could not demonstrate major efficacy in the control of nausea and the identification and implementation of antinausea agents into antiemetic regimens is highly warranted.

Patients receiving antiemetic treatment as recommended by international guidelines have an improved control of CINV, leading to a better treatment compliance and improvement in quality of life, however, only $50 \%$ of the patients receive antiemetic prophylaxis as recommended by the guidelines, causing a significantly worse protection from CINV, particularly for delayed CINV [31]. Therefore, the implementation of treatment guidelines in clinical practice is the pre-condition for effective prophylaxis of CINV.

\section{Conflict of interest}

The author declares that there is no conflict of interest.

\section{References}

[1] Feyer P, Jordan K. Update and new trends in antiemetic therapy: the continuing need for novel therapies. Ann Oncol, 22(1): 30-8, 2011.

[2] Hesketh PJ. Chemotherapy-induced nausea and vomiting. N Engl J Med, 358(23): 2482-94, 2008.

[3] Basch E, et al. Antiemetics: American Society of Clinical Oncology Clinical Practice Guideline Update. J Clin Oncol, 2011.

[4] Geling O, Eichler HG. Should 5-hydroxytryptamine-3 receptor antagonists be administered beyond 24 hours after chemotherapy to prevent delayed emesis? Systematic re-evaluation of clinical evidence and drug cost implications. J Clin Oncol, 23(6): 1289-94, 2005.

[5] Rojas C, et al. Palonosetron triggers 5-HT(3) receptor internalization and causes prolonged inhibition of receptor function. Eur J Pharmacol, 626(2-3): 193-9, 2010.

[6] Gralla R, et al. Palonosetron improves prevention of chemotherapyinduced nausea and vomiting following moderately emetogenic chemotherapy: results of a double-blind randomized phase III trial 
comparing single doses of palonosetron with ondansetron. Ann Oncol, 14(10): 1570-7, 2003.

[7] Aapro MS, et al. A phase III, double-blind, randomized trial of palonosetron compared with ondansetron in preventing chemotherapy-induced nausea and vomiting following highly emetogenic chemotherapy. Ann Oncol, 17(9): 1441-9, 2006

[8] Yu Z, et al. The efficacy and safety of palonosetron compared with granisetron in preventing highly emetogenic chemotherapy-induced vomiting in the Chinese cancer patients: a phase II, multicenter, randomized, double-blind, parallel, comparative clinical trial. Support Care Cancer, 17(1): 99-102, 2009.

[9] Saito M, et al. Palonosetron plus dexamethasone versus granisetron plus dexamethasone for prevention of nausea and vomiting during chemotherapy: a double-blind, double-dummy, randomised, comparative phase III trial. Lancet Oncol, 10(2): 115-24, 2009.

[10] Aapro M, et al. Double-blind, randomised, controlled study of the efficacy and tolerability of palonosetron plus dexamethasone for 1 day with or without dexamethasone on days 2 and 3 in the prevention of nausea and vomiting induced by moderately emetogenic chemotherapy. Ann Oncol, 21(5): 1083-8, 2010.

11] Likun Z, et al. A systematic review and meta-analysis of intravenous palonosetron in the prevention of chemotherapy-induced nausea and vomiting in adults. Oncologist, 16(2): 207-16, 2011.

[12] de Wit R. Current position of 5HT3 antagonists and the additional value of NK1 antagonists; a new class of antiemetics. Br J Cancer 88(12): 1823-7, 2003.

[13] Reddy GK, Gralla RJ, Hesketh PJ. Novel neurokinin-1 antagonists as antiemetics for the treatment of chemotherapy-induced emesis. Support Cancer Ther, 3(3): 140-2, 2006

[14] Navari RM. Fosaprepitant (MK-0517): a neurokinin-1 receptor antagonist for the prevention of chemotherapy-induced nausea and vomiting. Expert Opin Investig Drugs, 16(12): 1977-85, 2007.

[15] Grunberg S. Phase III randomized double-blind study of single-dose fosaprepitant for preveention of cisplatin-induced nausea and vomiting (CINV). J Clin Oncol, 28: 2010.

[16] Grunberg S, et al. Single-dose fosaprepitant for the prevention of chemotherapy-induced nausea and vomiting associated with cisplatin therapy: randomized, double-blind study protocol-EASE. J Clin Oncol, 29(11): 1495-501, 2011.

[17] NCCN. National Comprehensive Cancer Network; Antiemesis, C.P.G.i.O.-v.w.n.o.

[18] Roila F, et al. Guideline update for MASCC and ESMO in the prevention of chemotherapy- and radiotherapy-induced nausea and vomiting: results of the Perugia consensus conference. Ann Oncol, 21(Suppl. 5): v232-43, 2010.

[19] Hesketh PJ, et al. The oral neurokinin-1 antagonist aprepitant for the prevention of chemotherapy-induced nausea and vomiting: a multinational, randomized, double-blind, placebo-controlled trial in patients receiving high-dose cisplatin--the Aprepitant Protocol 052 Study Group. J Clin Oncol, 21(22): 4112-9, 2003.
[20] Poli-Bigelli S, et al. Addition of the neurokinin 1 receptor antagonist aprepitant to standard antiemetic therapy improves control of chemotherapy-induced nausea and vomiting. Results from a randomized, double-blind, placebo-controlled trial in Latin America. Cancer, 97(12): 3090-8, 2003

[21] Warr DG, et al. Efficacy and tolerability of aprepitant for the prevention of chemotherapy-induced nausea and vomiting in patients with breast cancer after moderately emetogenic chemotherapy. J Clin Oncol, 23(12): 2822-30, 2005.

[22] de Wit R, et al. Addition of the oral NK1 antagonist aprepitant to standard antiemetics provides protection against nausea and vomiting during multiple cycles of cisplatin-based chemotherapy. J Clin Oncol, 21(22): 4105-11, 2003.

[23] de Wit R, et al. The oral NK(1) antagonist, aprepitant, given with standard antiemetics provides protection against nausea and vomiting over multiple cycles of cisplatin-based chemotherapy: a combined analysis of two randomised, placebo-controlled phase III clinical trials. Eur J Cancer 40(3): 403-10, 2004.

[24] Rapoport BL, et al. Aprepitant for the prevention of chemotherapyinduced nausea and vomiting associated with a broad range of moderately emetogenic chemotherapies and tumor types: a randomized, double-blind study. Support Care Cancer, 18(4): 423-31, 2010.

[25] Einhorn LH, et al. Palonosetron plus dexamethasone for prevention of chemotherapy-induced nausea and vomiting in patients receiving multiple-day cisplatin chemotherapy for germ cell cancer. Support Care Cancer, 15(11): 1293-300, 2007.

[26] Boccia RV, et al. Efficacy and tolerability of transdermal granisetron for the control of chemotherapy-induced nausea and vomiting associated with moderately and highly emetogenic multi-day chemotherapy: a randomized, double-blind, phase III study. Support Care Cancer, 19(10): 1609-17, 2011.

[27] Jordan K, et al. Safety and efficacy of a triple antiemetic combination with the NK-1 antagonist aprepitant in highly and moderately emetogenic multiple-day chemotherapy. Eur J Cancer, 45(7): 1184-7, 2009.

[28] Tan L, et al. Clinical research of Olanzapine for prevention of chemotherapy-induced nausea and vomiting. J Exp Clin Cancer Res, 28: 131, 2009.

[29] Navari RM, et al. A phase II trial of olanzapine, dexamethasone, and palonosetron for the prevention of chemotherapy-induced nausea and vomiting: a Hoosier oncology group study. Support Care Cancer, 15(11):1285-91, 2007.

[30] Passik SD, et al. A phase I trial of olanzapine (Zyprexa) for the prevention of delayed emesis in cancer patients: a Hoosier Oncology Group study. Cancer Invest, 22(3): 383-8, 2004.

[31] Ihbe-Heffinger A, et al. The impact of delayed chemotherapy-induced nausea and vomiting on patients, health resource utilization and costs in German cancer centers. Ann Oncol, 15(3):526-36, 2004 